\title{
Residual Stress Evolution during the Manufacturing Process of Bearing Rings
}

\author{
CSEH David, ${ }^{1 a^{*}}$, BENKE Marton, ${ }^{2 b}$, MERTINGER Valeria, ${ }^{1 c}$, CZIBIK Adam, ${ }^{1}$
}

${ }^{1}$ Institute of Physical Metallurgy, Metalforming and Nanotechnology, University of Miskolc, MiskolcEgyetemvaros, Hungary

${ }^{2}$ MTA-ME Materials Science Research Group, University of Miskolc, Miskolc-Egyetemvaros, Hungary

acseh88david@gmail.com (corresponding author), bfembenke@uni-miskolc.hu, cfemvali@uni-miskolc.hu

Keywords: X-Ray diffraction, residual stress, $\sin ^{2} \Psi$ method, non-destructive measurements, stress tensor

\begin{abstract}
Residual stresses are the sources of the typical deformation failures of bearing rings called "ovality". An innovative X-ray diffractometer was used to measure the tangential residual stress state of bearing rings after the different manufacturing steps. The measurement requires no sample cutting, thus, the stress state of the same rings were measured. This way the evolution of the stress states of the same rings was possible to follow through their processing steps. It was shown that the residual stress state of the rings varied in a wide range from compressive to tensile stresses. It was also found that surface carburisation occurred at some positions on the circumference of some of the rings during heat treatment. The composition change resulted in a non-uniform stress distribution.
\end{abstract}

\section{Introduction}

Almost every production process such as forging, machining, rolling, cutting and the various types of heat treatments result a specific residual stress state (RS) $[1,2,3]$. The magnitude and type of the resulting residual stress may vary after each step of the production. Thus, the residual stress state of a final product depends on numerous factors. Furthermore, the stress state of the product may vary within a wide range. The production line of bearing rings consists of forging, cutting, heat treatment and machining. The most common failure of the bearing rings is a geometrical distortion called ovality. To avoid such failures, it is essential to be aware of the evolution of the residual stress state of the semi-products during the whole manufacturing line. [4,5,6].

In this manuscript a series of residual stress measurements using X-ray diffraction performed after the technological steps of production of bearing rings are presented. The aim was to monitor the evolution of the residual stress state of the bearing rings during the manufacturing line. The measurements were performed on the same inner and outer rings after the different productions steps. The technological processes were performed by the manufacturer.

\section{Experimental procedures}

The examined bearing rings were made of 100CrMn6 alloy according to the EN ISO 683-17 standard (C:1.0; Si:0.6; Mn:1.1; Cr:1.5 [wt.\%]). The outer and the inner rings were evolved from a common semi-product. The first step of the process was hot forging at $1190^{\circ} \mathrm{C}$. After this step the rings were cooled down to $700^{\circ} \mathrm{C}$ in ventilated air. The next step was the turning. This was followed by the severing and the separation of the inner and outer rings. After severing, the rings were hardened: austenized at $835^{\circ} \mathrm{C}$ for 40 minutes then cooled in a $190^{\circ} \mathrm{C}$ salt bath which was followed by tempering at $200^{\circ} \mathrm{C}$ for 25 minutes. The rings were placed in baskets (Fig. 1) during the full hardening process. The inner rings were just piled up in the baskets, but the outer rings were settled next to each other. Finally the hardened rings were finish-grinded. The stress states were measured after the hot forging ( $1^{\text {st }}$ step), the turning of outer ring $\left(2^{\text {nd }}\right.$ step), severing $\left(3^{\text {rd }}\right.$ step) and heat treatment $\left(4^{\text {th }}\right.$ step). The tangential residual stresses were measured at 12 positions (labelled from 0 to 11) on the middle perimeter of both inner and outer rings. The locations of the 12 measured 
positions were the same after each technological step. 5 parallel rings were examined after each processing get statistical data (project samples serial No. 1-5). After the $3^{\text {rd }}$ step only the outer rings were measured.

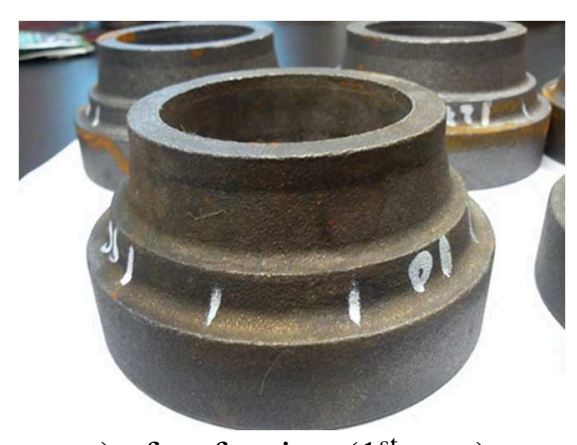

a) after forging $\left(1^{\text {st }}\right.$ step $)$

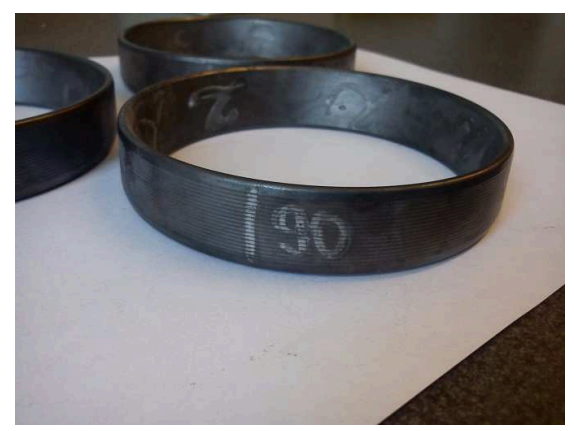

d) after heat treating $\left(4^{\text {th }}\right.$ step $)$.

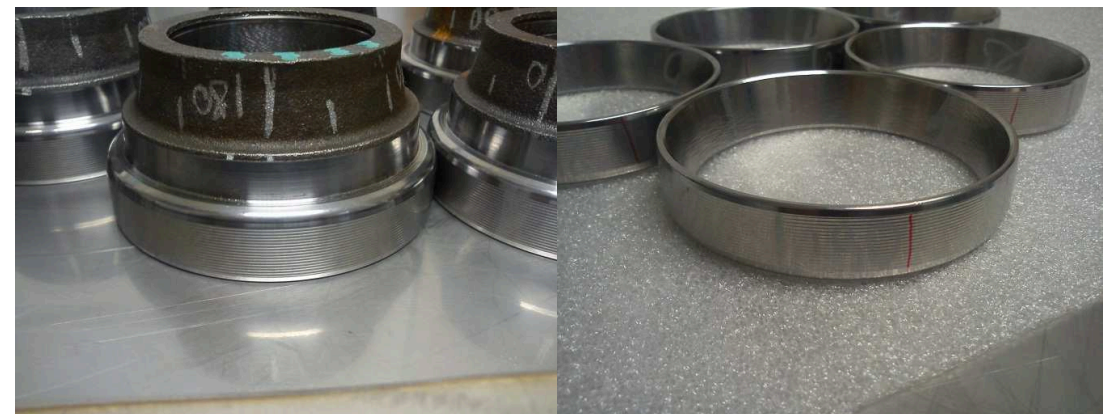

b) after turning of outer ring $\left(2^{\text {nd }}\right.$ step)

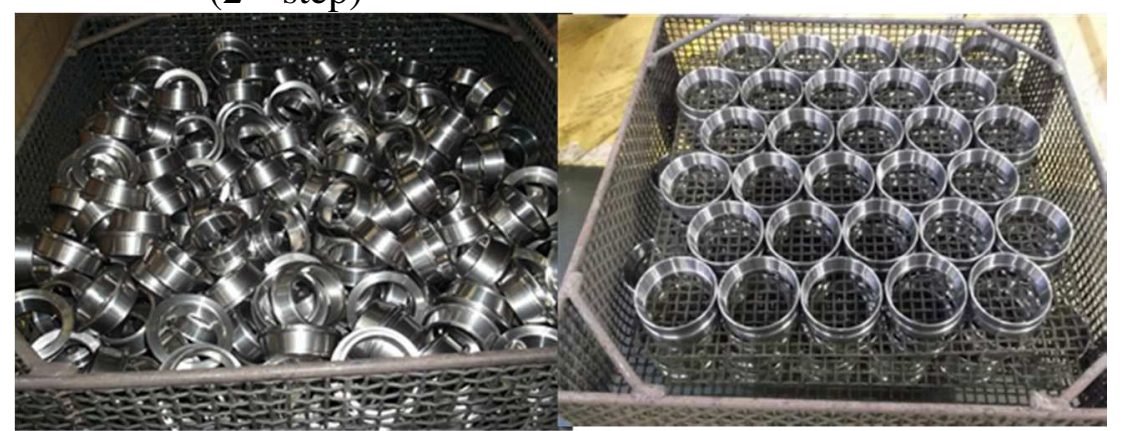

e) inner rings in the heat treating basket f) outer rings in the heat treating basket

Fig. 1 The bearing rings after the different manufacturing processes

A Stresstech Xstress 3000 G3R X-ray diffractometer developed especially for non-destructive residual stress measurements was used for the stress measurements. The speciality of this device is that the equipment tilted during the measurement instead of the sample $[3,7,8]$. This feature allows to perform measurements without sample cutting and made it possible to perform measurements on the same rings after the different production steps. Cr radiation was used to measure the (211) reflections of the samples. Data were recorded in 5 tilting positions in $\Omega$ mode in the $-35^{\circ}$ to $35^{\circ}$ interval with $10 \mathrm{sec}$ exposure time and $1 \mathrm{~mm}$ spot size. For the calculation the following material constants were used: Poisson's ratio $v=0.3$, Young's modulus $\mathrm{E}_{(211)}=211000 \mathrm{MPa}$. Residual stress profiles along depth were also measured on some rings (individual rings) after some of the production steps. For such examinations a Struers Movipol 5 mobile electrolytic polishing equipment was used to remove the surface layers of the material. A Mitutoyo displacement gauge was used for the depth measurements with one $\mu \mathrm{m}$ accuracy. Light and scanning electron microscopy (LM and SEM) were used for microstructure examinations.

\section{Results and discussion}

Fig. 2 shows the measured residual stress values of the rings after the $1^{\text {st }}$ processing step. The scatter of the measurements never exceeded $\pm 20 \mathrm{MPa}$, therefore they are not marked. Fig. 2a shows a compressive stress distribution between 150 and $250 \mathrm{MPa}$ for all of the 5 project outer rings. The circumferential stress distribution of the outer ring, project sample serial No. 1, 2 and 3 are quite similar, while the stress values of 4 and 5 show lower compressive stresses. On the latter two rings, a massive oxide layer remained after hot forging, therefore chemical etching had to be applied. Consequently, the material removal resulted in lower stress values. Fig. $2 b$ shows typical stress differences between the outer and the inner rings after hot forging (project sample No. 3). Smaller compressive stress was measured on the surface of the inner ring compared to the outer ones. A depth profile and the full with at half maximum (FWHM) parameters were also measured on an individual sample (Fig. 3.). 
Fig. 4 shows the residual stress data of both outer and inner rings after the $2^{\text {nd }}$ processing step. In this step only the outer rings were turned. Due to turning, the compressive stresses of the outer ring changed to intensive tensile stresses (Fig. 4a) while the inner rings preserved their stress states of the previous processing step (Fig. 4b).

The severing did not make any detectable changes in the stress state of the outer rings (Fig. 5a). The heat treatment (Fig. 5b) induced a near stress-free, relaxed condition. An increased scatter of data was observed after this step therefore an individual ring from another heat treatment series was also examined. Fig. 6 shows these results. The single data scattering of the project sample is higher than the individual sample. The circumferential stress state varied between zero stress and $\sim 300 \mathrm{MPa}$ in the individual sample. Two measuring positions (No. 0 and No. 3) were selected for comparative depth profile measurements to obtain the reason of the stress state differences. The results are shown in Fig. 7. An unusual tensile stress value was measured at the surface at the measuring position No. 3 of the individual sample, while the same stress distribution was measured at position No. 0 of the heat treated individual sample and in the heat treated project ring. At position No.3 of the individual ring, the $\sim 330 \mathrm{MPa}$ tensile stresses occurred only at the surface and converged to 0 MPa with increasing depth. In $50 \mu \mathrm{m}$ depth, the stress-free state was reached. Thus, the scatter of the heat treated sample and the observed unusual tensile stress of the outer ring are a surface effect. Microstructure investigations were performed to describe the source of this surface effect.

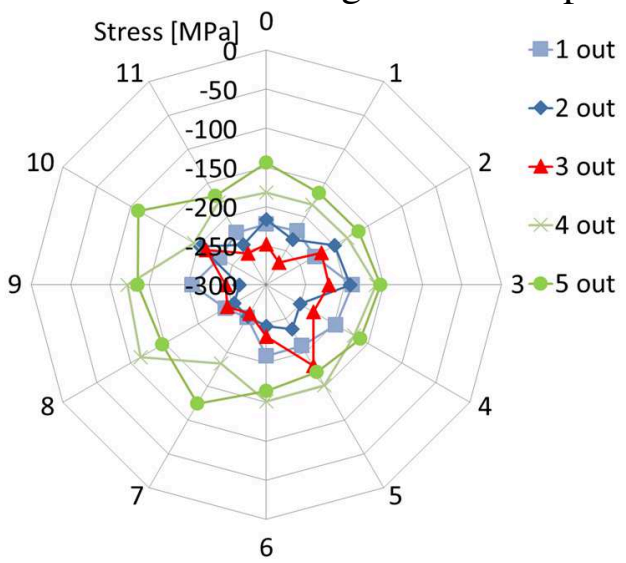

a)

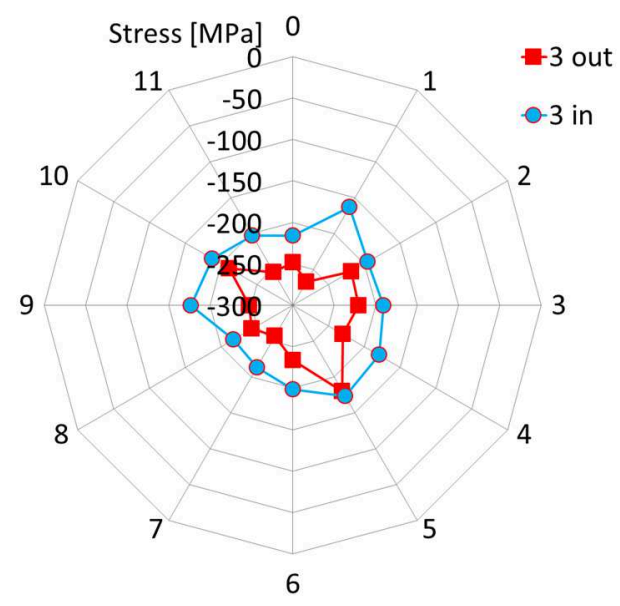

b)

Fig. 2 Circumferential residual stress distribution after hot forging ( $1^{\text {st }}$ step): a) outer rings (1-5 serial numbers) and b) RS comparison between outer and inner ring

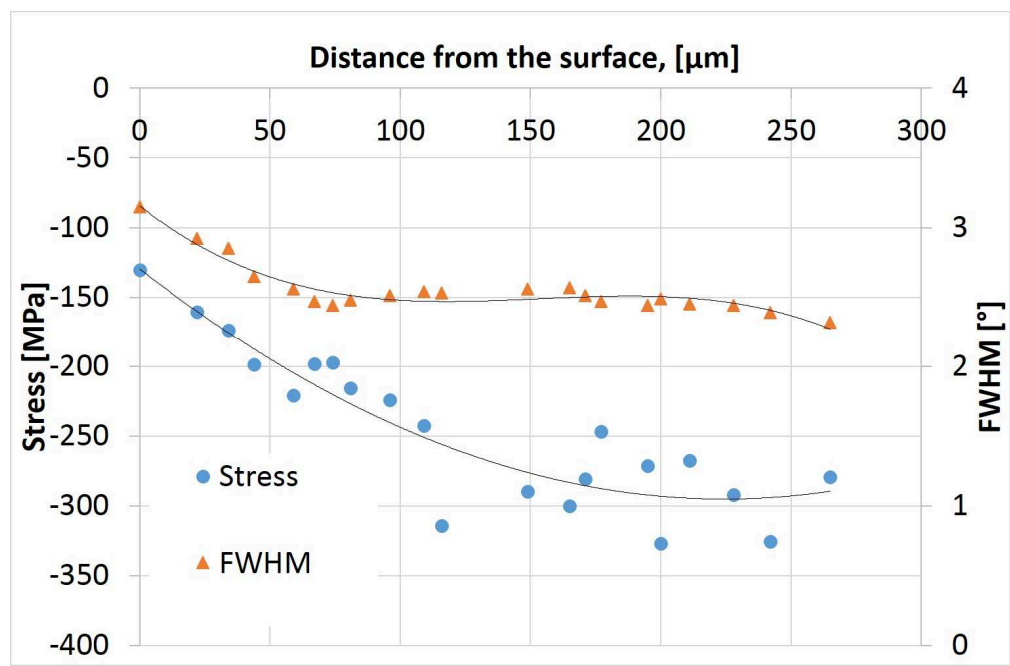

Fig. 3 Depth profile of residual stress and FWHM after the hot forging ( $1^{\text {st }}$ step). 


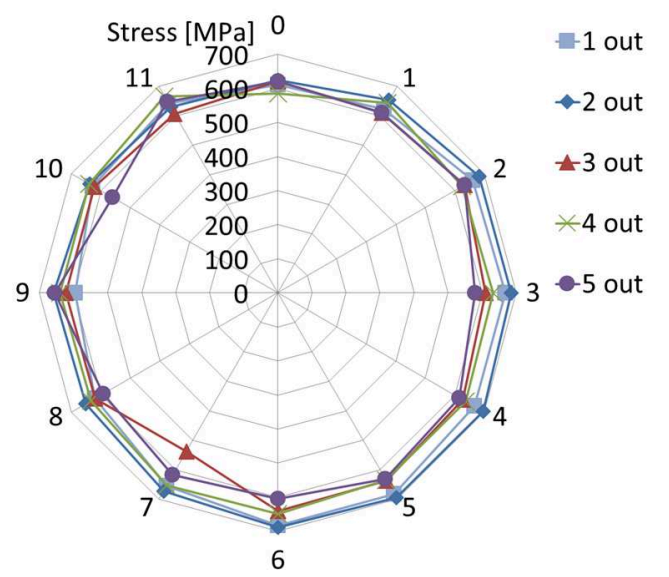

a)

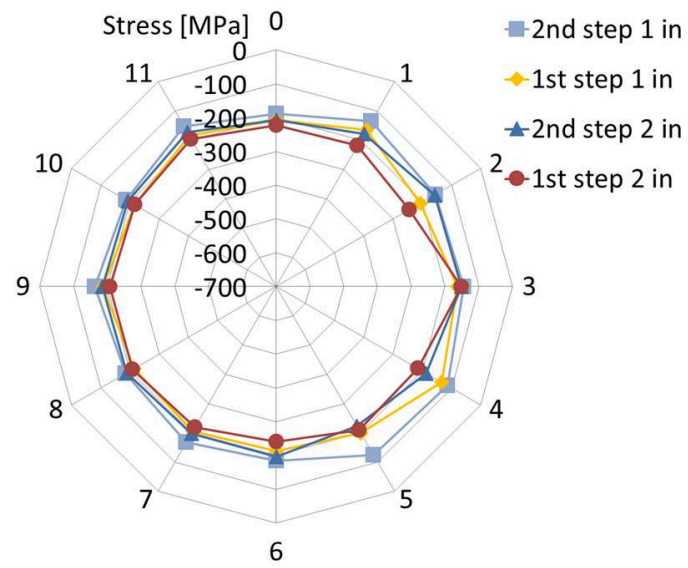

b)

Fig. 4. Circumferential residual stress distribution after turning of outer ring ( $2^{\text {nd }}$ step): a) RS in outer rings (1-5 serial numbers) and b) RS comparison in inner ring (1-2 serial numbers) after the $1^{\text {st }}$ and $2^{\text {nd }}$ step

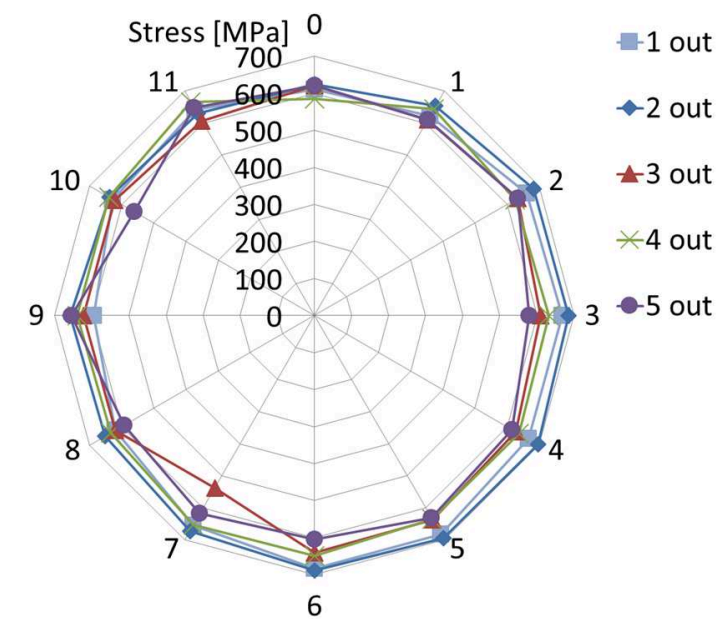

a) $3^{\text {rd }}$ step

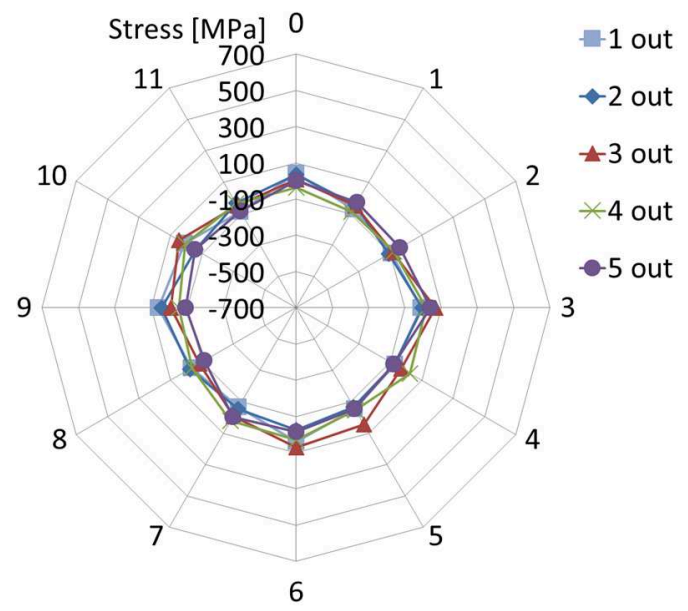

b) $4^{\text {th }}$ step

Fig. 5. Circumferential RS distribution in outer rings (1-5 serial numbers): a) after severing ( $3^{\text {rd }}$ step) and b) after heat treating $\left(4^{\text {th }}\right.$ step)

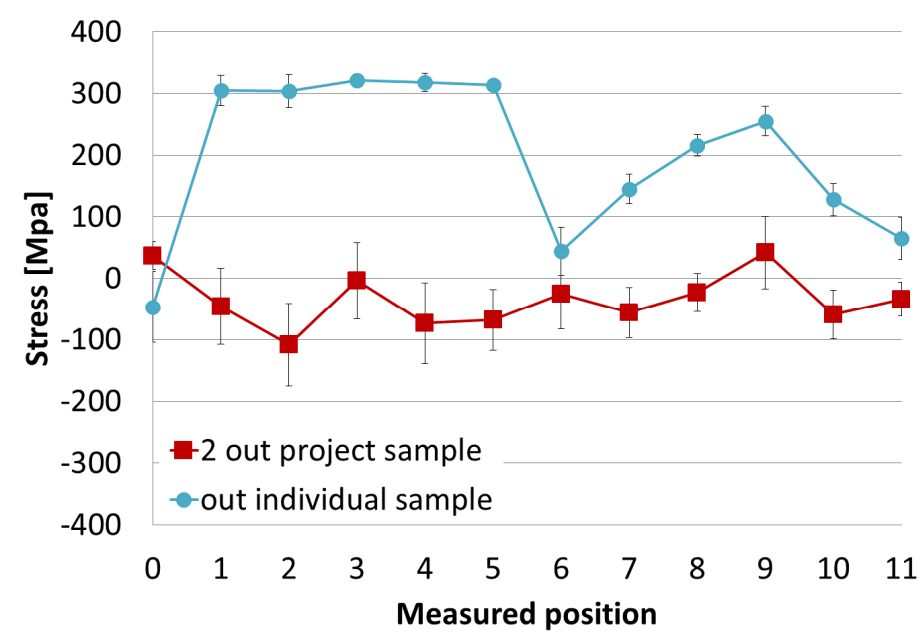

Fig. 6. Compared circumferential RS distribution of the heat treated individual sample and the heat treated project sample serial No.2, which also presented in Fig. 5, out - outer ring 


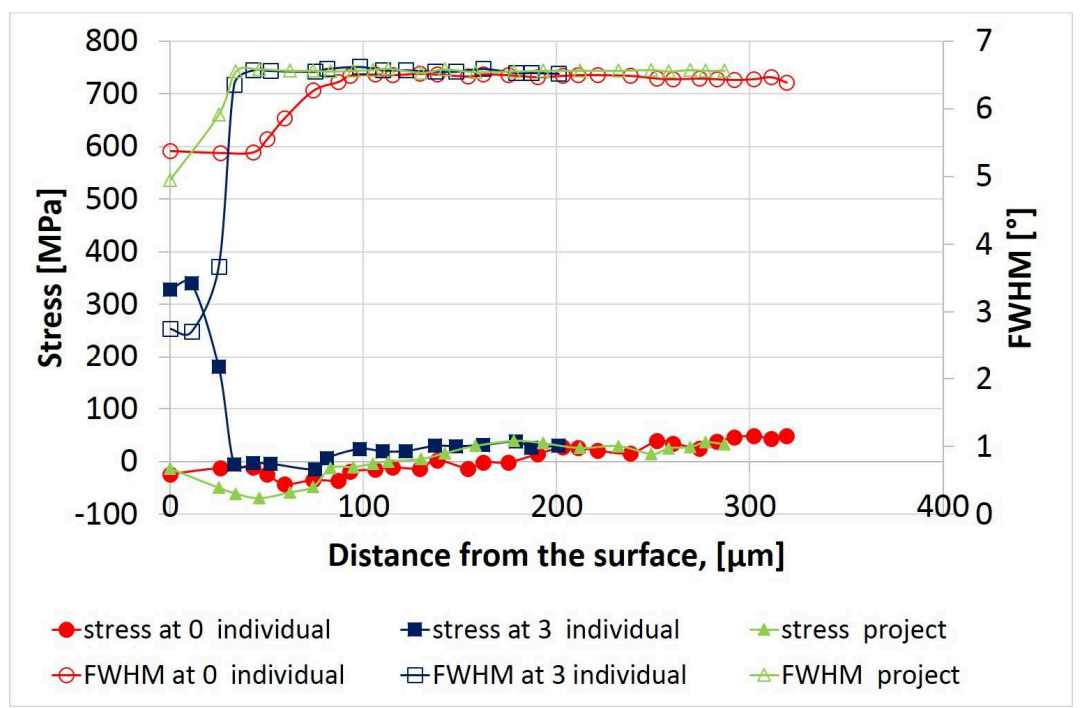

Fig. 7. Depth profile of residual stress and FWHM at the 0 and 3 surface position of the heat treated individual sample and a project sample.

Fig. 8 shows the microstructure of the cross section of the sample where the depth profile was taken. The top of the picture shows the outer surface of the rings. The increasing compressive stress on the depth profile is associated with the three different layers of structure formed after the forging being decarbonized layers, lamellar perlite and spheroidal structure (Fig. 8a). After the heat treatment the homogeneous tempered martensite structure is present in the project sample (Fig. 8b). The source of the different stress distribution can be seen in Fig. 8c and d. The coarse martensite structure in the near-surface region can be associated with the high tensile stress at measuring position No. 3. of the individual sample. The stress-free structure at measuring position No. 0 shows isotropic grain size (black rectangles in Fig. 8c. and d). The different microstructure is usually a consequence of the different concentration of the sample which can be resulted from the processes occurring during the heat treatments such as oxidation, carburation or decarbonisation. These processes can occur because of the improper atmosphere in the heat treating furnace. The values of the full width at half maximum (FWHM) of the diffraction profiles are of the best parameters to show the concentration inhomogeneity of the samples. If the surface layer is decarbonised (Fig. 8a) the FWHV is increased (Fig. 3) and the structure can maintain a smaller compressive stress. The heat treated individual sample at measuring position No. 3 shows the opposite effect in Fig. 7. The increased carbon concentration on the near-surface region can be associated with the coarser martensite structure (Fig. 8c).

\section{Summary}

A series of residual stress measurements using X-ray diffraction was performed after the different technological steps of the production of bearing rings were presented. The measurements were performed on the same inner and outer rings after the production steps which were hot forging turning, severing and hardening heat treatment. The tangential residual stresses were measured at 12 positions on the middle perimeter of both inner and outer rings. It was shown that the stress values of the rings vary between 600 and $-200 \mathrm{MPa}$ during the processing line. Some individual samples were also examined to demonstrate the stress distribution along depth. The significance of each technological step was demonstrated and the effects of the heat treatment failures such as decarburisation, carburation, and oxidation were also presented. The effect of carburisation and decarburisation in the near surface region during the heat treatment were observed by microstructure analysis and the change in the full width at half maximum values (FWHM) of the diffraction peaks used for the stress calculations. 


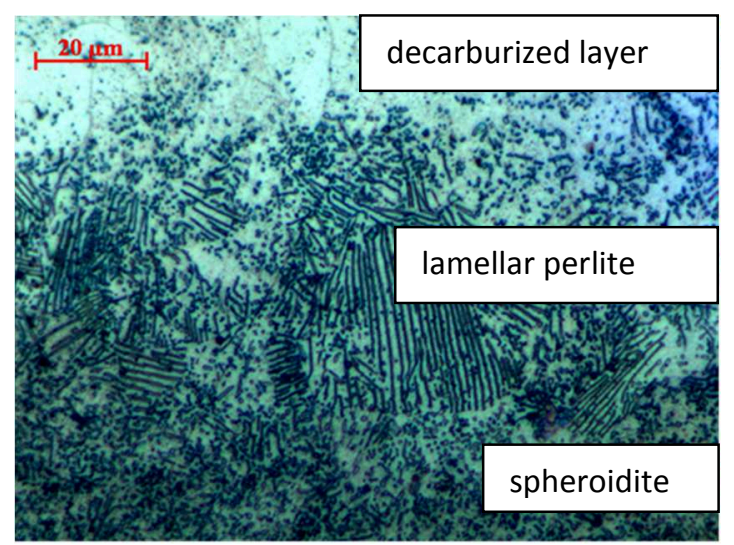

a) after hot forging $\left(1^{\text {st }}\right.$ step $)$

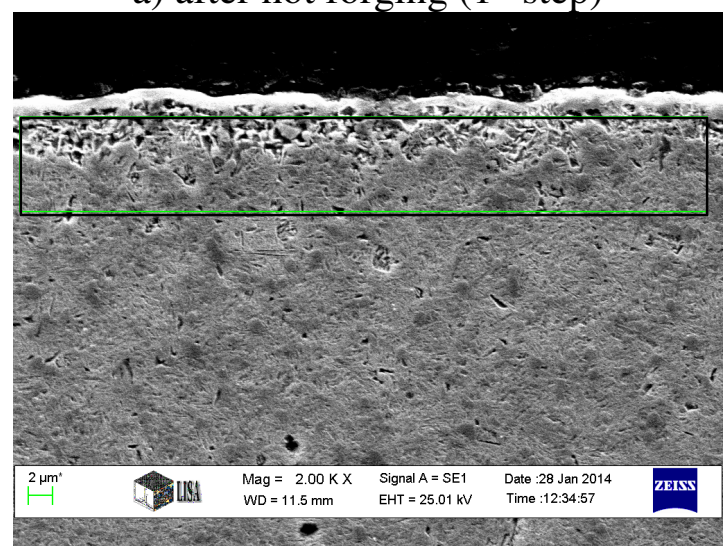

c) after heat treating $\left(4^{\text {th }}\right.$ step $)$, individual sample, measuring point $n .^{\circ} 3$.

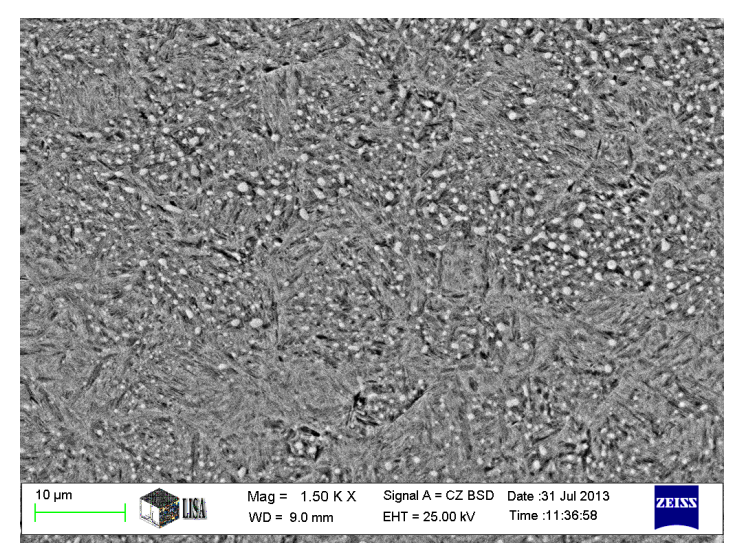

b) after heat treating $\left(4^{\text {th }}\right.$ step) project sample

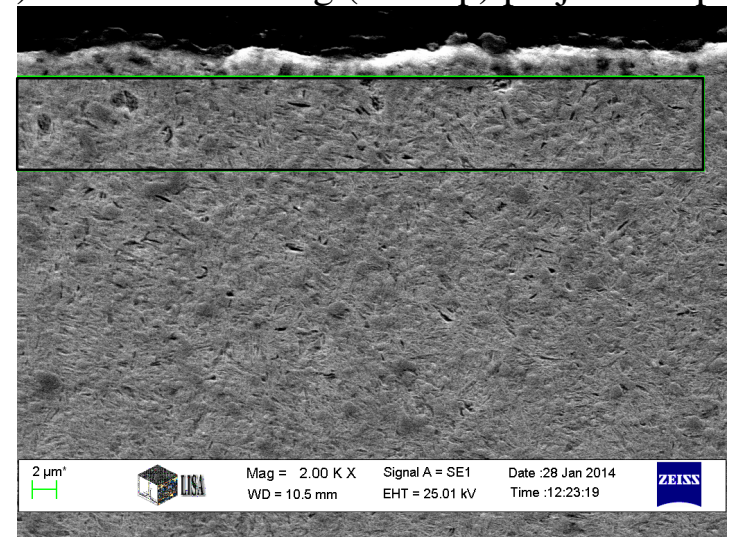

d) after heat treating $\left(4^{\text {th }}\right.$ step), individual sample, measuring point $n .^{\circ} 0$.

Fig. 8. Depth profile of microstructure feature. Top of the picture presents the outer surface of the rings

\section{Acknowledgement}

This work has been carried out as part of the TÁMOP-4.2.1.B-10/2/KONV-2010-0001 project within the framework of the New Hungarian Development Plan. The realization of this project is supported by the European Union, co-financed by the European Social Fund. The authors thank to Valéria Szabó-Gyurján and the FAG Magyarország Ipari Kft. for the treating of the samples and Árpád Kovács for the SEM pictures.

\section{References}

[1] Heat treating ASM Handbook Vol. 4, ASM International 1991, USA pp. 606-607

[2] Handbook of Residual Stress and Deformation of Steel, ASM International 2008, USA pp.347-

[3] A. D. Krawitz: Introduction to diffraction in materials science and engineering, John Wiley 2001, pp.119-143,278-318

[4] J. Epp, H. Surm, T.Hirsch, F. Hoffmann, Residual stress relaxation during heating of bearing rings produced in two different manufacturing chains, Journal of Materials Processing Technology 211 (2011) 637-643

[5] N.S. Rossini, M. Dassisti, K.Y. Benyounis, A.G. Olabi, Methods of measuring residual stresses in components, Materials and Design 35 (2012) 572-588

[6] H.K.D.H. Bhadeshia, Steels for bearings, Progress in Materials Science 57 (2012) 268-435

[7] P. J. Withers, H. Bhadeshia: Residual Sress Part1- Measurement techniques, Mat Sci and Technology, April 2001 Vol17 pp.355-365

[8] Gray S. Schajer Practical residual stress measurement methods, John Wiley 2013, pp. 140-161 